\title{
Physical Characteristics of Stream Subbasins in the Cottonwood River Basin, Southwestern Minnesota
}

\author{
By Christopher A. Sanocki
}

\begin{abstract}
Data that describe the physical characteristics of stream subbasins upstream from selected points on streams in the Cottonwood River Basin, located in southwestern Minnesota, are presented in this report. The physical characteristics are the drainage area of the subbasin, the percentage area of the subbasin covered only by lakes, the percentage area of the subbasin covered by both lakes and wetlands, the main-channel length, and the main-channel slop?. The points on the stream include outlets of subbasins of at least 5 square miles, outlets of sewage treatment plants, and locations of U.S. Geological Survey low-flow, high-flow, and continuous-record gaging stations.
\end{abstract}

\section{Introduction}

This is the ninth report in a series of reports detailing subbasin characteristics of streams in Minnesota and adjacent states. The Cottonwood River Basin drains an area of 1,310 square miles and is represented by hydrologic accounting unit 07020008 (U.S. Geological Survey, 1974). The Cottonwood River Basin includes parts of Lyon. Murray, Cottonwood, Redwood, and Brown Counties in southwestern Minnesota.

Selected data for points on streams at outlets of subbasins larger than about 5 square miles; at outfalls of sewage treatment plants; and at locations of U.S. Geological Survey low-flow, high-flow, and continuousrecord gaging stations located in the Cottonwood River Basin are presented in this report.

This report was prepared in cooperation with the Minnesota Department of Transportation.

\section{Acknowledgments}

The Minnesota State Planning Land Management Information Center (LMIC), provided assistance with the digitizing and programming needed to produce this report. Tom E. Kujawa, a graduate student at Mankato State University and Jim L. Krumrie, a student at the University of Minnesota, did much of the digitizing and assisted in the preparation of this report. Their contributions were essential for the completion of this report.

\section{Methods}

U.S. Geological Survey 7-1/2 minute series topographic maps were used as source maps to obtain the areas for the subbasin boundaries, lakes, marshes, the main-channel length, and the contour elevation points used in this report. Paper copies of the maps were used. A geographic information system (GIS) was used to define the geographic location and exten ${ }^{+}$of the subbasins, lakes, marsh, main-channels, an t elevation points described below. Data digitized from paper copies were in error by no more than twice the horizontal accuracy of National Mapping Standards of 40 feet (Thompson, 1987, p. 104). All thematic(digitized) data were projected into an Albers Equal-Area projection for storage and anal-rsis.

Subbasin boundaries were delineated on the basis of human activities and topographic contours. Human activities, such as the installation of storm sewers, the drainage of wetlands, and the diversion of streams, may alter the drainage area of the stream. Data from field inspections and recent drainage-ditch maps, therefore, were transferred to the topographic maps. The subbasin boundaries were digitized by LMIC using a GIS.

Lake and marsh data were digitized using a computer-aided drafting (CAD) system and transferred to the GIS. Lake and marsh boundaries were overlaid on the subbasin boundaries to associate each lake and marsh with a subbasin. The total area of lakes and marshes within each subbasin was calculat ${ }^{d}$ by the GIS. Total marsh area plus total lake area i - defined as storage area. Lake data was digitized by th: Minnesota Department of Transportation and updated by the U.S. Geological Survey, Minnesota. Marshes were digitized by the U.S. Geological Survey, Minnesota.

Main channels were delineated for each subbasin on the 7-1/2 minute topographic maps starting at the outflow of the subbasin and continuing upstream. 
Whenever the main channel joined with another stream, the stream upstream of the junction that drained the largest area was selected as the main channel. The main channel is continuous and is defined as a single trace that passes through marshes, lakes, and the midline of rivers and braided streams from the basin outlet to the point within the basin that drains the greatest area; this is generally the basin divide. The main channels were digitized by U.S. Geological Survey, Minnesota, using a CAD system and transferred to the GIS. The main channel data were overlaid onto the subbasin data to associate each main channel with its subbasin.

Elevation points were digitized at the intersection of topographic contour lines and main channels. The elevation data was recorded using a CAD system and transferred to the GIS. The elevation data was overlaid onto the main channel data to associate each elevation data point with a main channel. Two points on the main channel, at 10 percent and at 85 percent of the main channel length from the basin outlet to the drainage divide, were located by the GIS. The elevations of these two points were interpolated from the digitized elevation data. Main-channel slope was calculated by dividing the difference in elevation between these points by the distance along the stream channel between these points.

\section{Physical Characteristics of Cottonwood River Subbasins}

Physical characteristics determined for each of the subbasins shown on plate 1 are presented in table 1 . Subbasins are presented in order from headwaters to mouth. The rank of the subbasin stream is shown by indentation; whenever two subbasin streams joined, the stream draining the least cumulative area was assigned a lower rank and indented in the table.

The data for drainage area, main-channel length, and main-channel slope are reported using three significant figures or rounded to the nearest one-hundredth of a unit. The data for lake area and storage area are reported using two significant figures or rounded to the nearest one-tenth of a percent. 1:

The following is an explanation of terms used in table

Subbasin number. A seven digit number based on the Minnesota Common Stream and Watershed Numbering System (Minnesota Department of Natural Resources, 1981). The first two digits are 29 and identify the Cottonwood River Basin. The following five digits are arbitrary and are used to identify each individual subbasin.
Stream name. The name of the stream or ditch shown on U.S. Geological Survey 7-1/2 minute topographic maps. The relative position of the subbasin above other subbasins, streams, gaging stations, and outfalls from sewage treatment plants also is given.

Outlet location. The U.S. Public Lands Survey System is used to describe the location the stream exits the subbasin, down to quarter-quarter section. The description includes quarter-quarter section, section, township, and range.

Drainage area. That area, measured on a horizontal plane, enclosed by a topographic divide, within which direct surface runoff from precipitation normally flows by gravity into a watercourse above a specific point. This may include closed basins and other areas that do not contribute directly to surface runoff.

Lake area. The percentage of the drainage area covered by open water as shown on $7-1 / 2$ minute topographic maps.

Storage area. The percentage of a drainage area covered by open water and marshes as shown on 7-1/2 minute topographic maps. Marsh areas are not shown on plate 1 .

Main-channel length. The total Iength of the main channel from the basin outlet to the point within the basin that drains the greatest area; this is generally the drainage divide. The main channel is the watercourse that drains the greatest area.

Main-channel slope. The average slope of the watercourse between the points at 10 and at 85 percent of the distance along the main channel from the basin outlet to the drainage divide.

\section{References Cited}

Minnesota Department of Natural Resources, 1981, The Common Stream And Watershed Numbering System: Minnesota Department of Natural Resources Stream Inventory and Data Retrieval Systems Report 7002, unpaged.

Thompson, M.M., 1987, Maps for America, Third edition: U.S. Geological Survey, 265 p.

U.S. Geological Survey, 1974, Hydrologic unit map-1974 State of Minnesota: 1 plate, scale 1:500,000. 


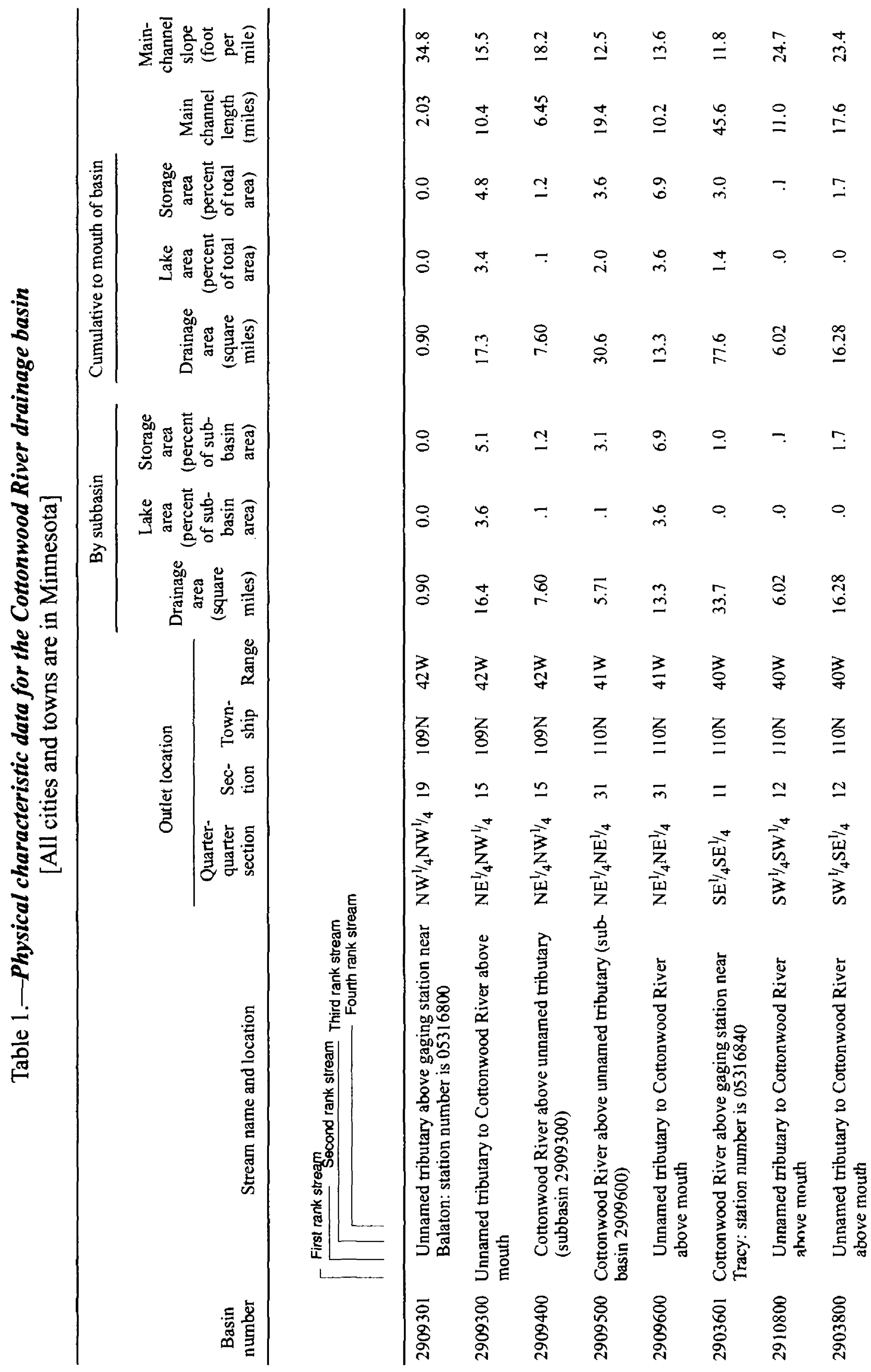




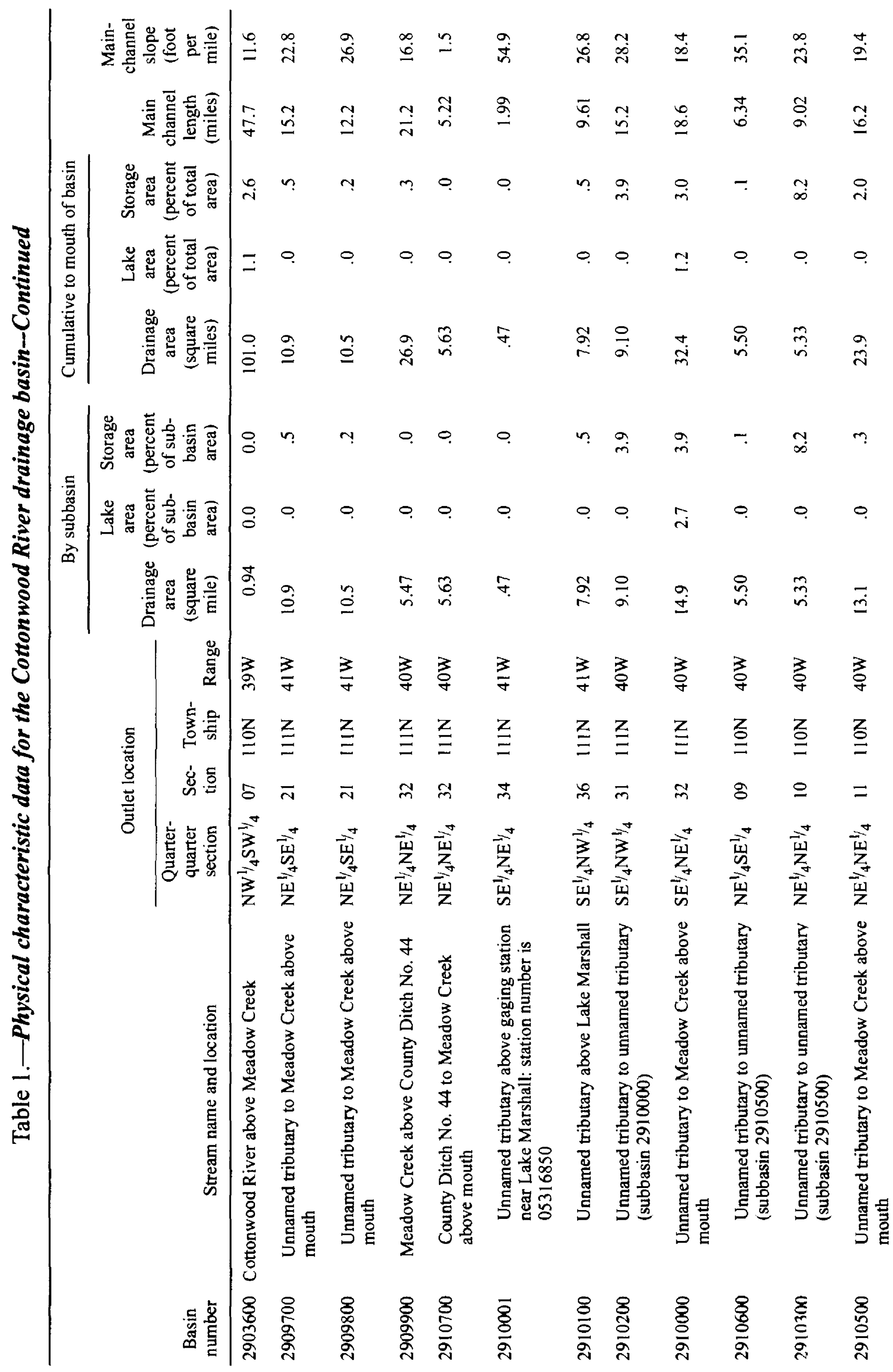




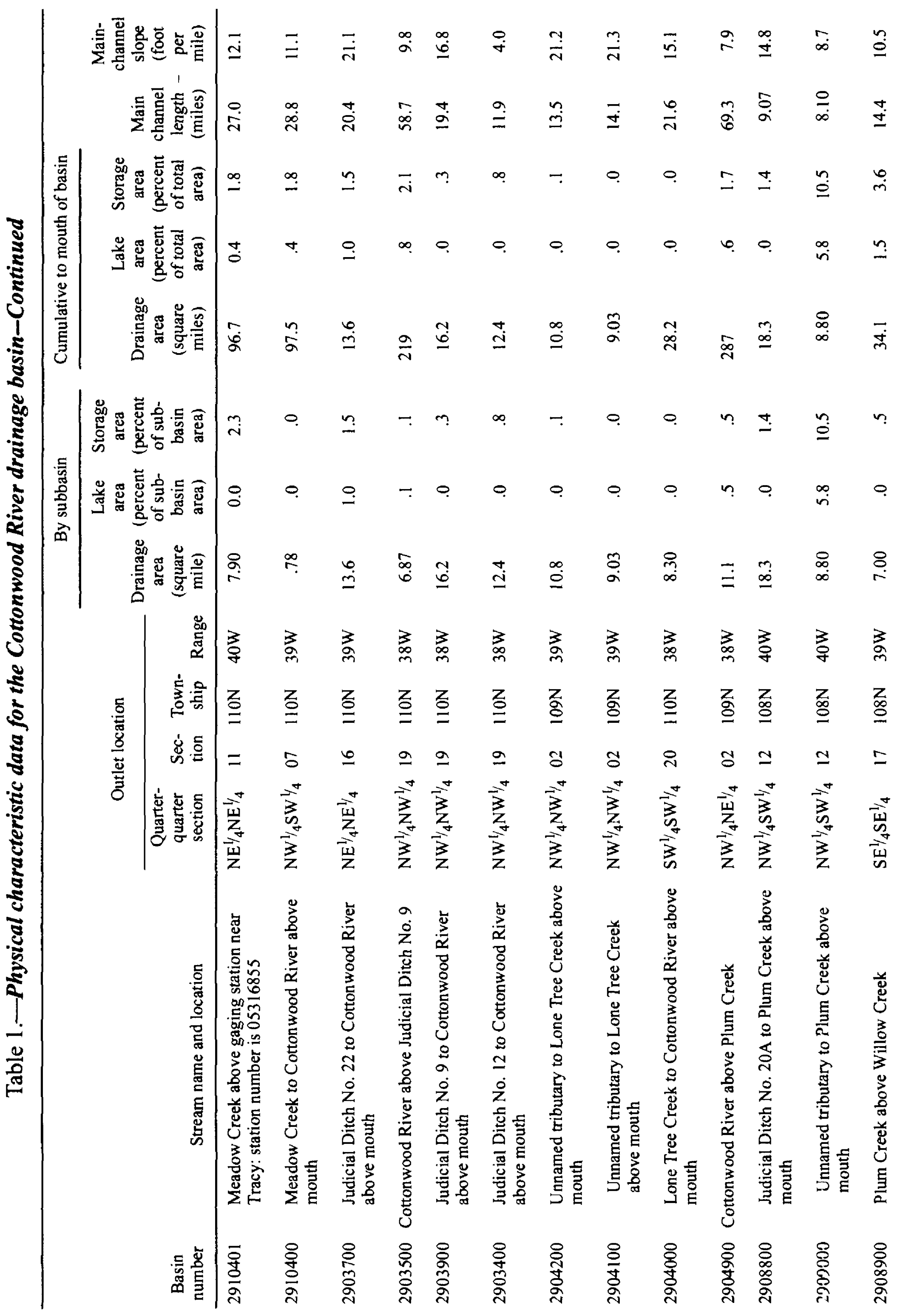




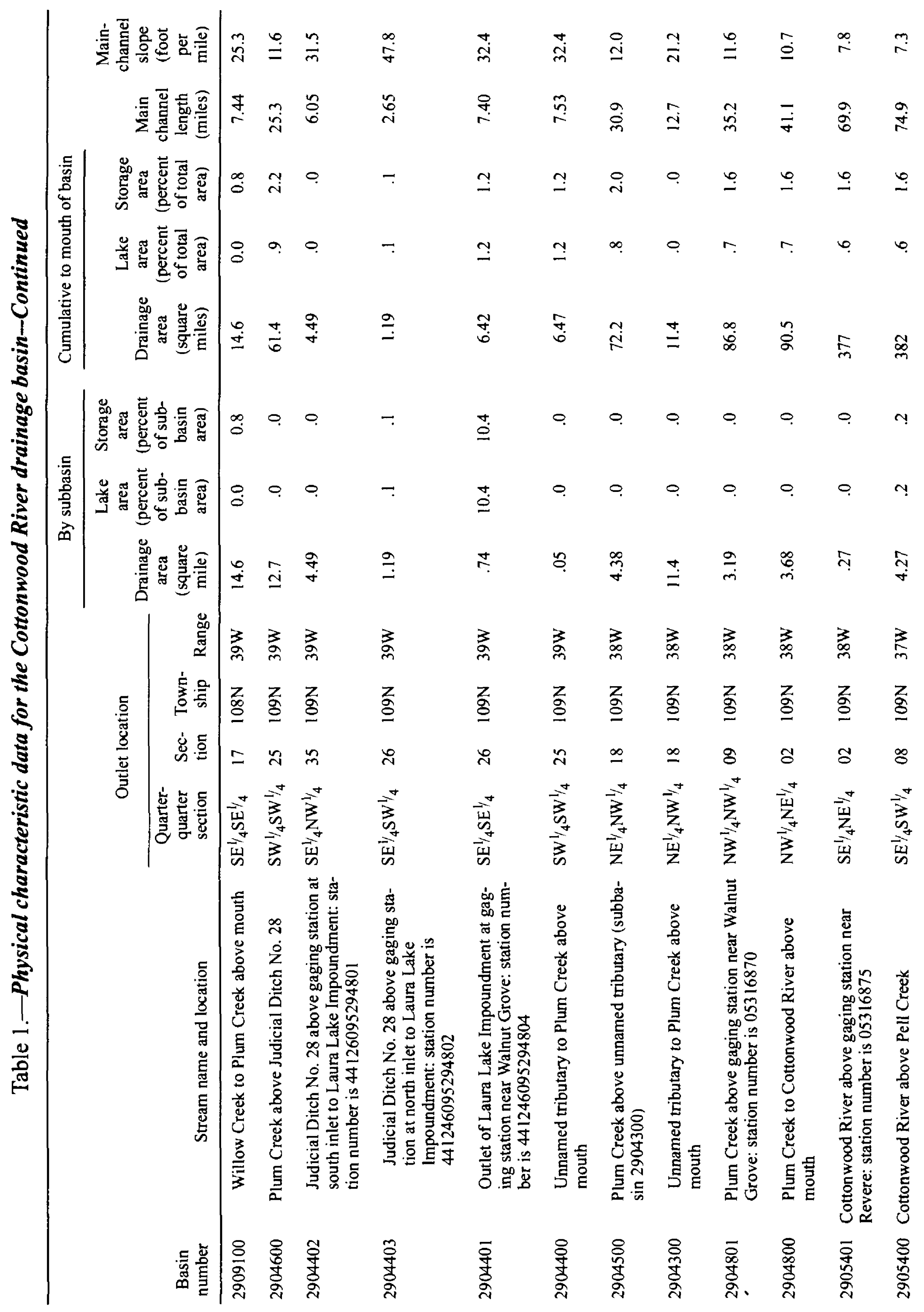




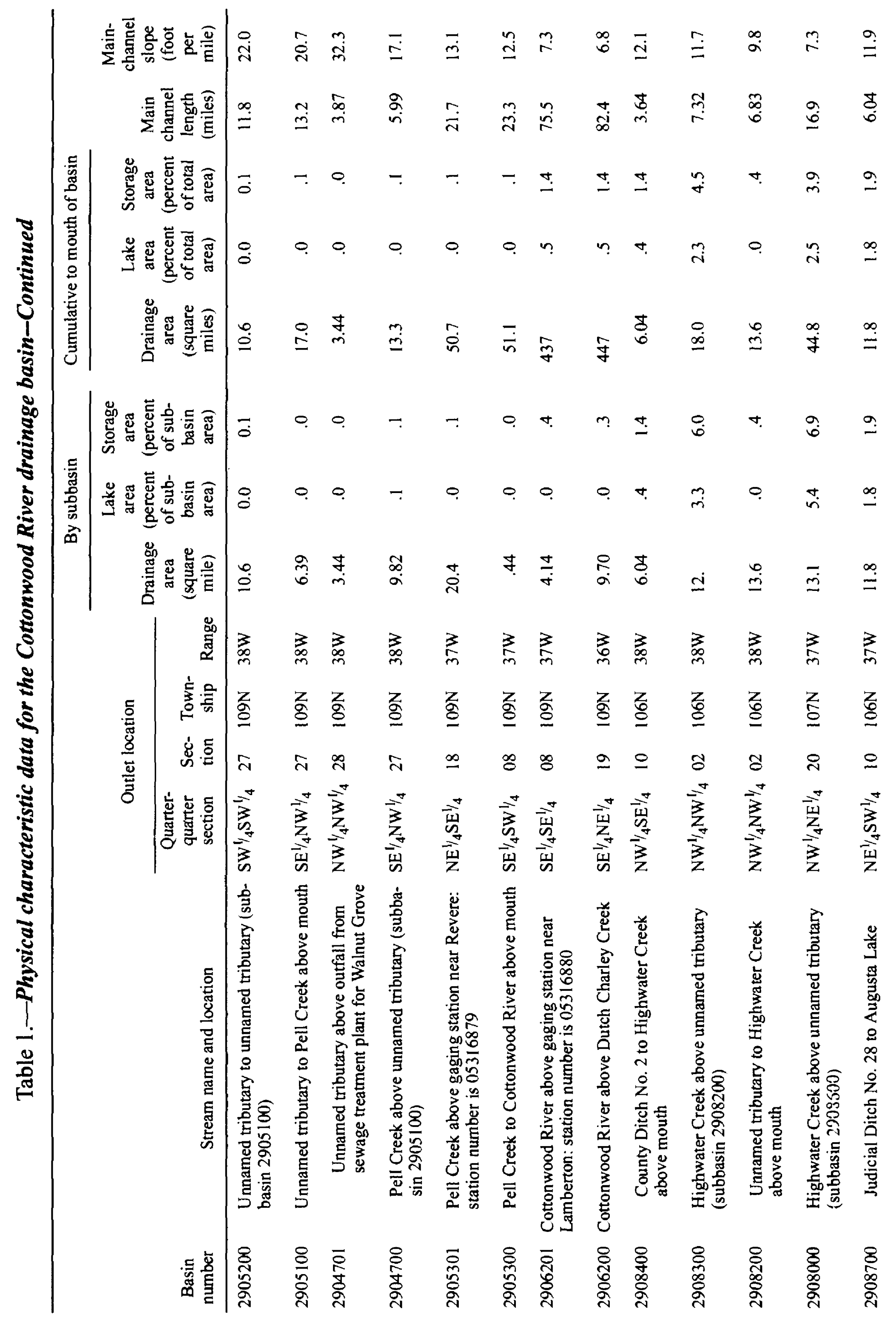




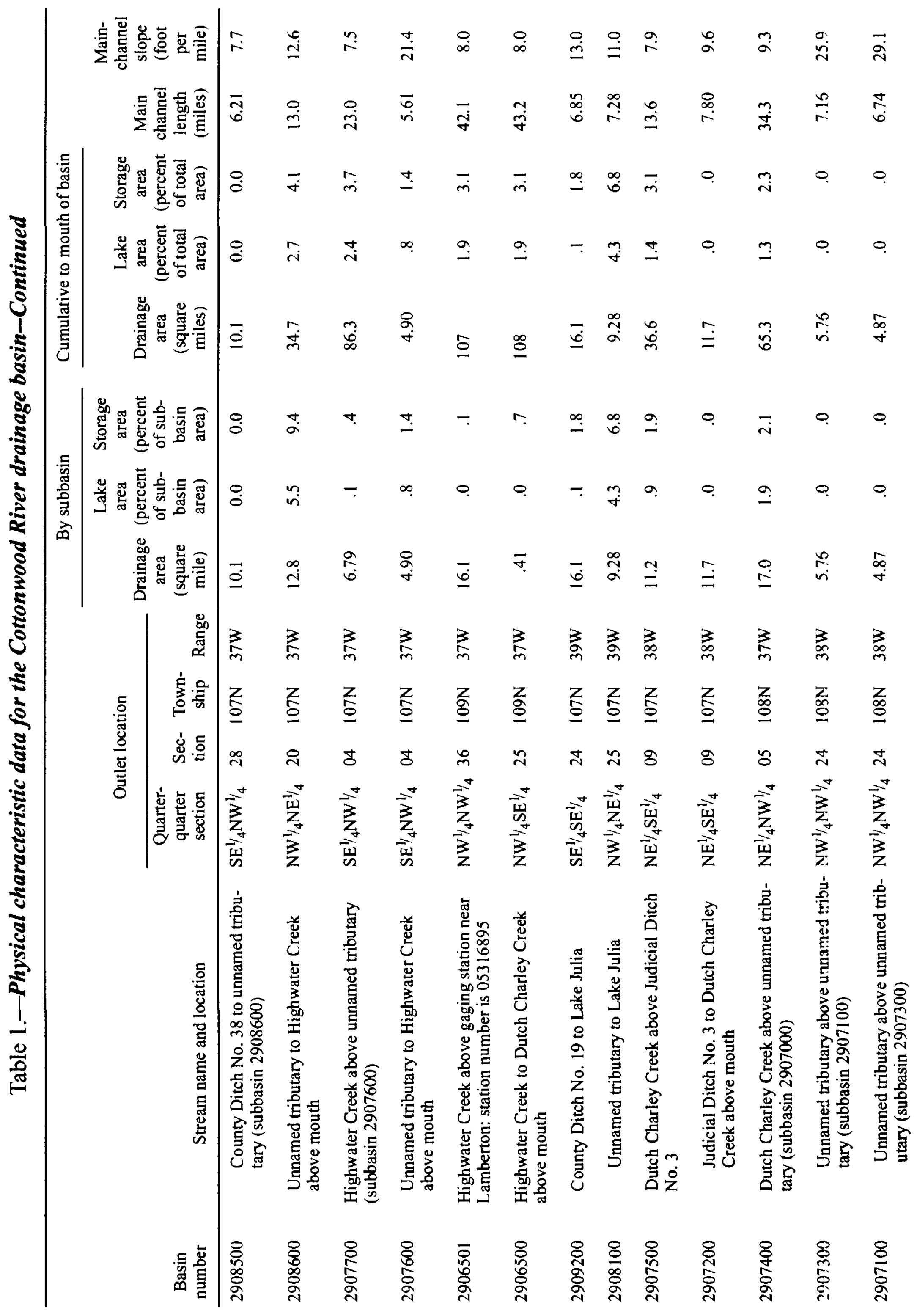









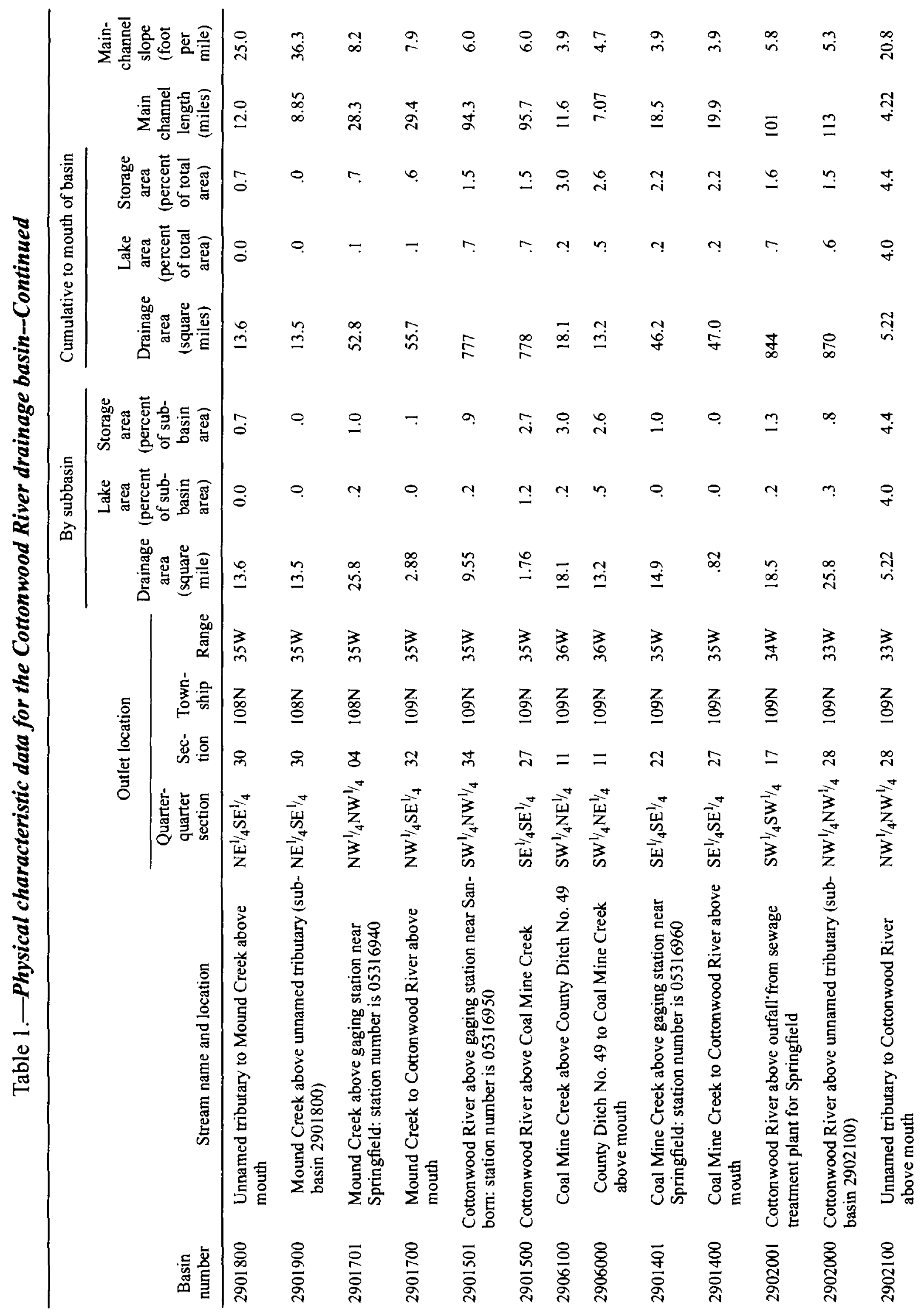




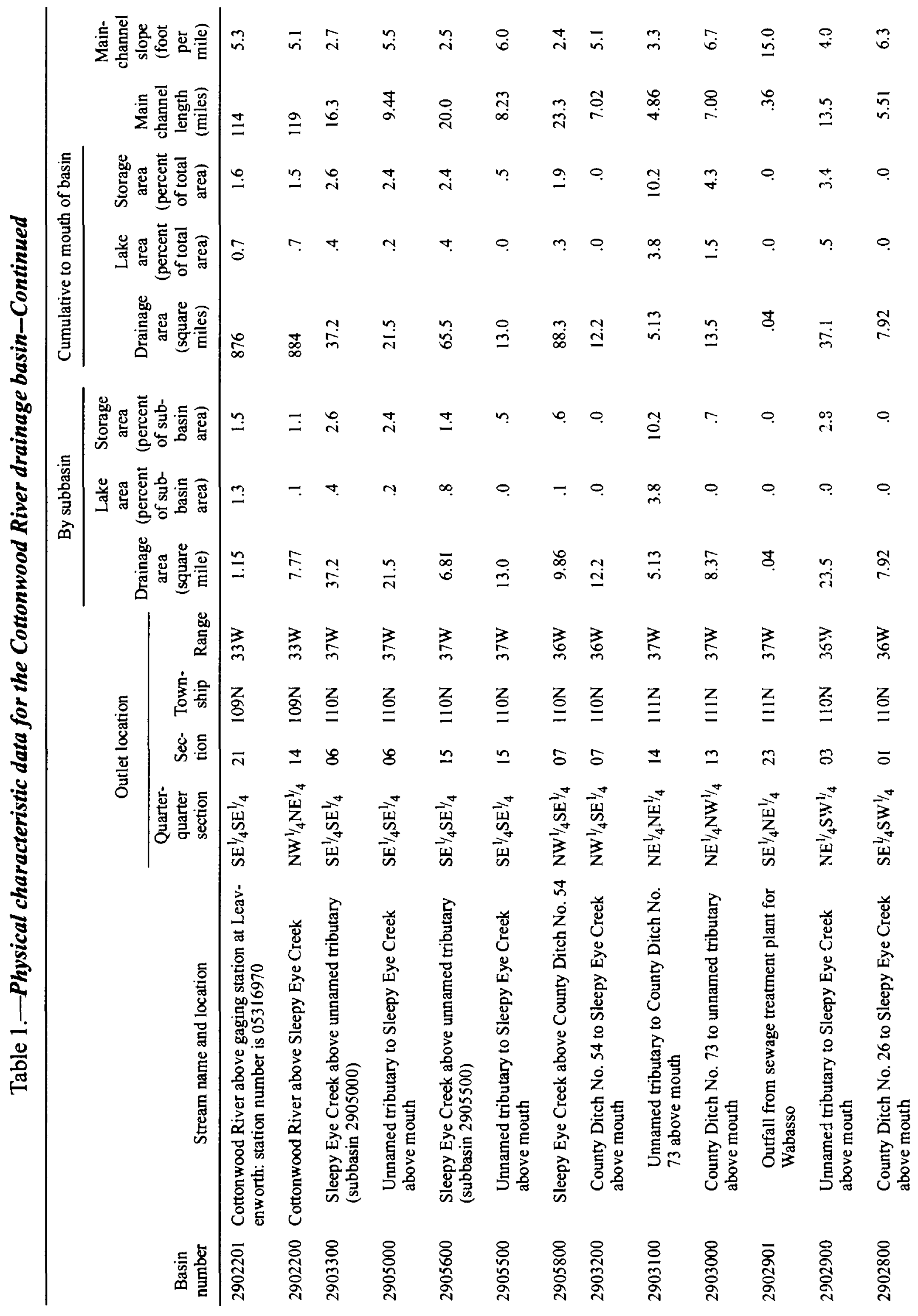




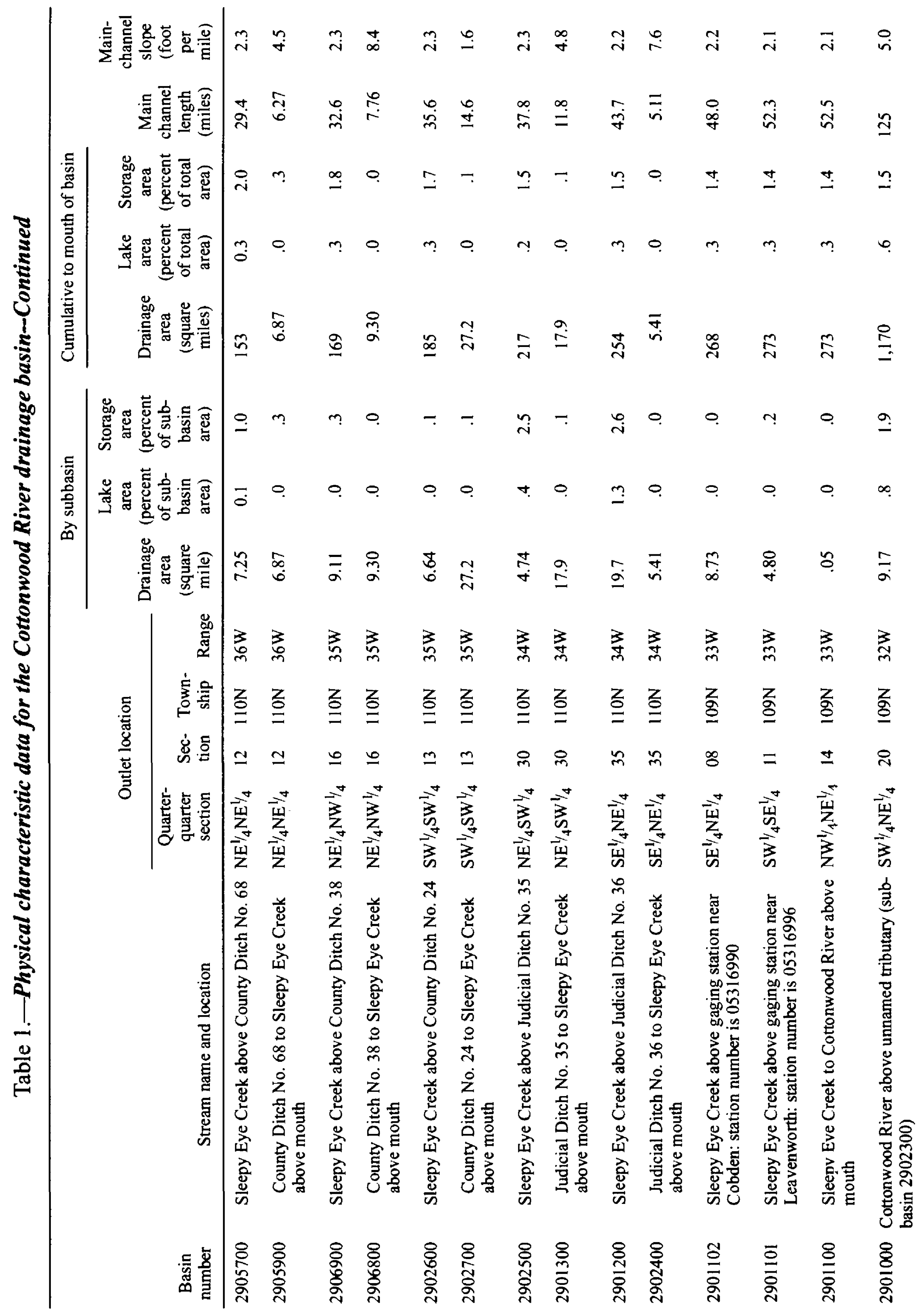




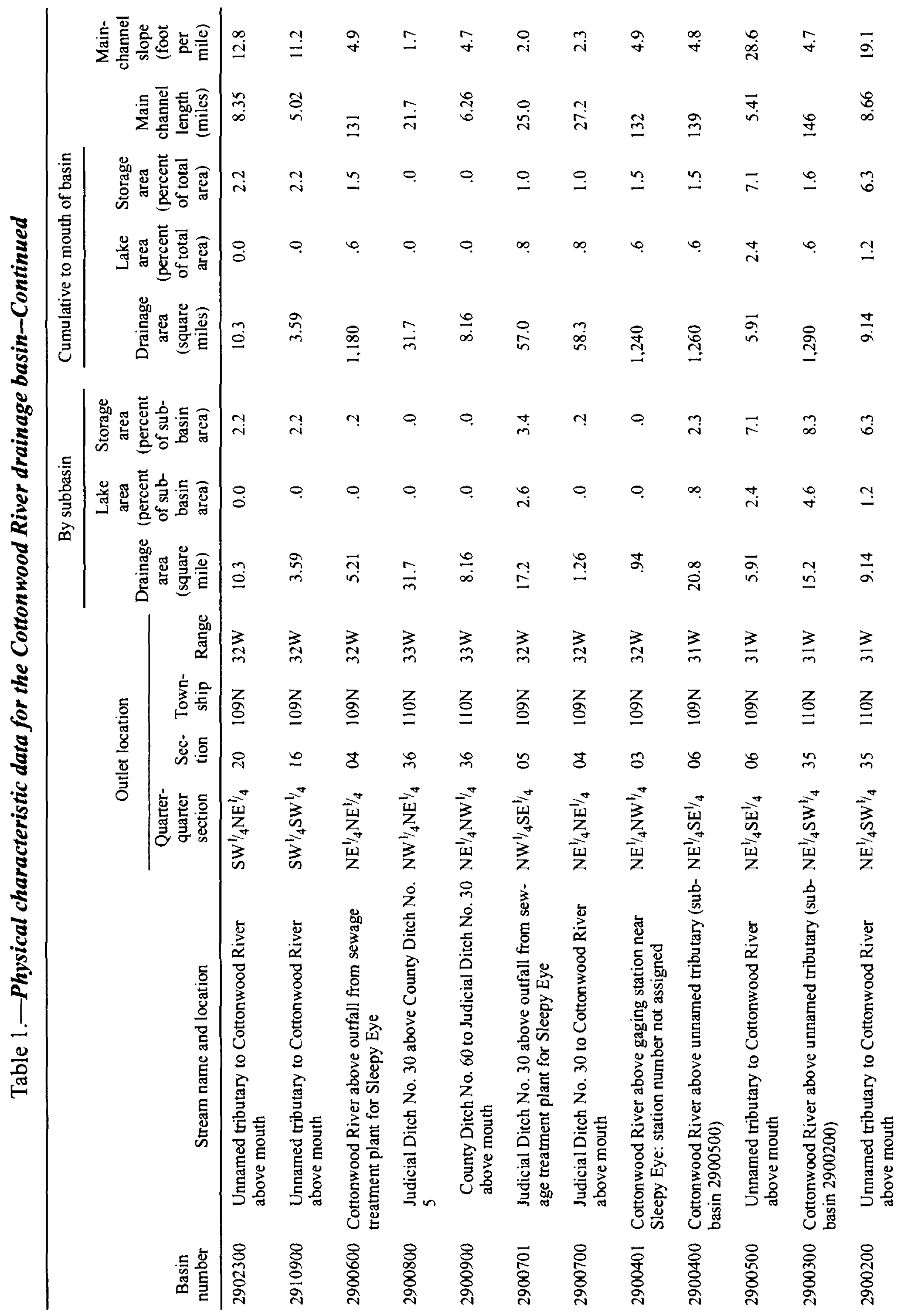




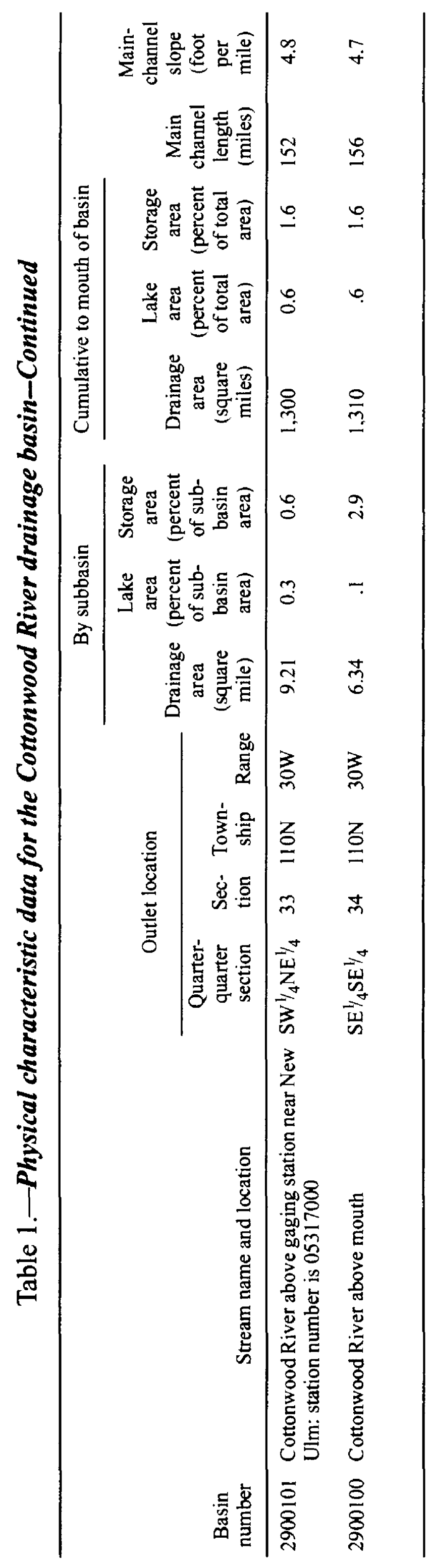

